\title{
Integrating Mental Health in Welfare Evaluation: An Empirical Application
}

\author{
Sanghamitra Das \\ Abhiroop Mukhopadhyay \\ Tridip Ray ${ }^{1}$ \\ Indian Statistical Institute, New Delhi
}

15 August 2007

\begin{abstract}
This paper presents simple measures of individual and family mental health indices based on axiomatic foundations and integrates mental health into a neoclassical model that allows for proper substitution possibilities in the family preferences and quantifies its significance in family utility. We find that mental health effects are far more important than the effect of consumption or children's schooling in determining family utility. We illustrate the usefulness of our approach by considering the case of HIV/AIDS experience in India. Using our approach, we find that while there are no significant differences in per capita consumption and schooling between HIV and NON HOV families, the cost of HIV/AIDS are still considerably large due to the inclusion of mental health. Integrating mental health in a utility maximization framework helps us quantify these costs.
\end{abstract}

\footnotetext{
${ }^{1}$ We are thankful to the World Bank for funding this study. We are also thankful to Dr. Anshu Goel, who specializes in treating HIV/AIDS patients, for answering our numerous questions and helping us with the health measurement data. We thank Dr. Phanender Khera, Dr. Archana Phuke, Dr. Sanjay Swain, the NGO SEED of Andhra Pradesh, the NGO Aruna of Orissa for guiding us in interviewing the patients. Thanks are also due to our surveyors D. Tiwari, S. Mishra, M. Kumar, R. Khowal, M. Durai, P. Gurunaidu and Anandraj who had to travel to remote areas, stay under very uncomfortable conditions and ask sensitive questions to the many suffering families. Needless to say, we are very grateful to the families who patiently answered our long survey and confided their unpleasant experiences to us. Inputs from Clive Bell, Shanta Devarajan, Michele Gragnolati, the seminar participants at the Indian Statistical Institute (Delhi), the World Bank and the International Food Policy Research Institute have been very helpful. We also thank the conference participants at the 2006 South and South East Asia Econometric Society Meeting and at the Conference on Sustainable Development and Livelihood at the Delhi School of Economics (2007). Errors, if any, are the authors' sole responsibility.
} 


\section{Introduction}

In this paper we offer a methodology to integrate mental health in welfare evaluation by allowing for proper substitution possibilities in family preferences. We present simple measures of family mental health based on axiomatic foundations and quantify their significance in family utility. We use a health problem - the HIV/AIDS experience in India - to illustrate the general procedure of how to integrate mental health into the standard family optimizing framework.

It is widely accepted in medical sciences that mental health is a key component of health. Economic analysis has traditionally shied away from modeling mental health as it requires data on psychological aspects that are not easily or directly measurable. Empirical studies have “dealt with” such factors by lumping them under the blanket term 'unobserved heterogeneity' and have, instead, focused on effects of 'observed' factors.

Recently, however, in the social sciences attempts have been made to understand the importance of such traditional unobservables, as in the pioneering studies of correlation between happiness and economic performance (Clark and Oswald, 1994 and 1997). There is a growing body of literature on happiness and mental well-being (see, for example, Blanchflower and Oswald, 2004, 2007; Case and Deaton, 2006; Easterlin, 2003; Frey and Stulzer, 2002; Gilbert, 2006; Graham, 2007; Helliwell, 2006; Kahneman et al, 2006; Layard, 2005). The mental well-being research has proven to be well-suited in situations where revealed preferences provide limited information such as welfare effects of unemployment, divorce, smoking, drug abuse and so on.

This literature combines the techniques of economists and psychologists and highlights factors other than income that affect well-being. It is in its early stage of development and most of it attempts to show the relation of mental health with observed characteristics. Some have focused on determinants of happiness and mental well-being through reduced-form regressions (see, for example, Andres, 2004; Blanchflower and Oswald, 2004, 2007; Case and Deaton, 2006; Helliwell, 2006). Effects on mental health have also been analyzed in the context of studying effects of policies. For example, recent

work by Kling, Liebman and Katz (2007) looks at, among other things, the effect of 
housing voucher schemes on mental health and finds substantial impact. We take off from this reduced-form literature and move towards structural analysis (see Keane, 2006).

We use data on 850 families in India and estimate family utility function parameters that measure the relative importance of consumption, schooling of children and mental and physical health effects. We model families making choices on medical expenditure to buy expected future physical health, which in turn affects their current mental health. Our estimates reveal that families' weight on mental health far exceeds that on consumption or on their children's schooling.

The choice of 850 families in our sample is not purely random. Of these surveyed families, 371 are families where there is at least one member infected by HIV (HIV families). We include HIV families for two reasons: Firstly, the HIV experience in India gives us a unique opportunity to integrate mental health in the utility maximization framework because according to counsellors and doctors working with HIV patients in India, what strikes them the most about HIV patients is the psychological effect. The statistical implication of our sampling is the inclusion of the lower end of the mental health spectrum which increases the variation in our mental health variable thus leading to more robust estimates than we would have obtained by considering only the general population. However, in our estimation procedure, we use weights to take into account that we have over-sampled HIV families (HIV/AIDS prevalence in India is only $0.36 \%$ in the 15-49 age group). Thus our results may be taken to be that for a typical family in India.

Secondly, the choice of HIV families also allows us to conduct an illustrative exercise to show the usefulness of our methods. In the context of HIV families, our data reveals that income losses, which a traditional approach would tend to focus on, are partly made up by transfers from relatives. Hence, to calculate the welfare loss of HIV to families, it becomes imperative to obtain a measure of mental health rather than treat it as 'unobserved heterogeneity'. In this paper, we do so and provide an estimate of the loss due to HIV/AIDS to a family in India.

The paper is organized as follows. Section 2 discusses the data while section 3 discusses the construction of the two health indices: physical and mental. Section 4 
motivates the model while section 5 presents the estimation procedure. The estimation results are presented in section 6. Section 7 illustrates an application to calculate the welfare loss to a family due to HIV/AIDS. Some robustness checks are carried out in section 8. Section 9 discusses the contribution of this paper and concludes.

\section{Data}

Primary data was collected on 479 NON HIV families and 371 HIV families. Since it is more difficult to survey HIV families and problems of endogeneity are more likely to be an issue in that context, we first start with a discussion of the sampling procedure used to survey them.

Due to the sensitive nature of the disease and the fear of stigma, we felt that we could not succeed if we just carried out a random sample or sent out forms to doctors and NGOs all across the country. The responses, if any, would most likely be endogenous. So our approach was to use exogenous sampling, one that is not correlated with HIV/AIDS incidence, so that usual econometric methods are applicable with minor modifications (such as the use of weights).

In order to ensure the necessary trust of patients, we expected that only doctors who knew us (including some of our field surveyors who had worked with HIV patients earlier) personally would agree to the surveying of their patients and the latter would trust our word of confidentiality. Hence we started with our physicians network in New Delhi, who referred us to other doctors/NGOs in various parts of the country. We followed up these contacts and ended up with data from some of the high prevalence states (Tamil Nadu, Andhra Pradesh and Maharashtra) as well as some of the low prevalence states (Delhi, Uttar Pradesh and Orissa). The number of states chosen and the sample size were constrained by a one year time limit imposed by our funding agency. ${ }^{2}$ Even though this sample is not random, it is not a result of endogenous sampling either. The criterion on

\footnotetext{
${ }^{2}$ The doctors/NGOs explained the motives of our study to their patients but the choice to be surveyed was ultimately left to individual patients. Almost all of them agreed to be surveyed. Consent forms were signed by all. But the identities of patients surveyed through the NGOs are known to the NGOs only. Patients of doctors were mainly surveyed at the hospital or clinic of the doctors. We do have identifying information for most but these surveys are physically with us and such information is separated from the data in order to maintain current and future confidentiality.
} 
which our sampling was done is uncorrelated to the nature of HIV/AIDS infection. Hence standard econometric methodology is valid.

To control for environmental factors, the complement sample of 479 families where there is no reported incidence of HIV (NON HIV families) was based on geographic proximity (same village or same residential cluster in a town).

\section{Health Indices}

Next let us discuss some of the crucial health indices used in our estimation procedure.

\subsection{Physical Health}

The survey asked a number of questions on the occurrence of common symptoms of infection (fever, diarrhoea, cough and cold, loss of appetite, general body ache, and head ache). Moreover questions were asked regarding some diseases and symptoms that are seen more often in HIV patients than NON HIV such as tuberculosis, knots, oral ulcers, and genital ulcers. The reference period for the above symptoms was the last three months. ${ }^{3}$

Given the symptoms, we took the help of an expert in HIV treatment at a government clinic, who assigned a numerical index based on the symptoms for all the HIV and NON HIV respondents. We use this index as a measure of morbidity. The index ranges from 1 to 11 with 11 being the healthiest and 1 being of the worst health. Table 1 summarizes this health index by HIV status.

Since our analysis is at the family level, we construct the average health of a family by taking the mean over the health of existing adults in the family. This controls for different number of adults in families. Thus, as expected, HIV families have lower physical health as compared to NON HIV families.

\footnotetext{
${ }^{3}$ We are aware that health experts are in favour of much shorter reference periods, for example last 15 days. We extended the period to pick up the fact that HIV patients do, on the average, have higher morbidity but go through periods of 'normal' health and so we wanted a long enough period to pick up this difference.
} 


\subsection{Mental Health}

We construct an index of mental health based on self-reported occurrence of depression related feelings of the respondent and his/her spouse (for married respondents). Questions on feelings were asked using the questions in Case and Deaton (2006). ${ }^{4}$ The following statements were made and the respondents were asked if in the last 15 days the occurrence of the feeling captured by each statement was "Hardly ever", "Sometimes", "Most of the time" or "Never".

o I felt that I could not stop feeling miserable, even with the help of my family and friends;

o I felt depressed;

o I felt sad;

o I cried a lot;

o I did not feel like eating; my appetite was poor;

o I felt everything I did was an effort;

o My sleep was restless.

The ranking of mental health was made explicit by giving a number to each answer: "Never" was given 4 points, "Hardly ever" 3 points, "Sometimes" 2 points and "Most of the time" 1 point. Using these values, we construct a mental health index $\left(I M H_{1}\right)$ : minimum of the points across all questions answered by the respondent and, where present, by his/her spouse. This is the Rawlsian "maximin" criterion and is characterized by some basic axioms regarding aggregation (Sen, 1986). It does not rely on cardinality (as an average would have). But it assumes comparability of this ordinal measure across different subjects. It also gives equal importance to all questions. To check if choice of index makes a big difference, we also consider another index which is similar in its Rawlsian flavour but uses responses to only one question: "I felt depressed" $\left(\mathrm{IMH}_{2}\right)$.

\footnotetext{
${ }^{4}$ We use the questionnaire in Case and Deaton (2006) as it was already tested on a sample of 1000 households in 100 villages in Udaipur district in India. The same sample has also been used by Banerjee, Deaton and Dufflo (2004).
} 
Both these indices are ordinal. Hence a higher value of the index implies higher mental health. Table 2 summarizes the distribution. It is clear that the distribution of $I M H_{1}$ as well as $I M H_{2}$ for NON HIV families always dominates the distribution for HIV families. Thus NON HIV families are mentally better off whichever index one considers.

\section{The Model}

In this section we develop a model to integrate mental health into a standard utility maximization problem. The unit of analysis is the family consisting of, where present, the man, the woman, and the children who are less than or equal to 18 years of age $^{5}$. We assume that all the economic decisions of the family, including the decisions for the children, are taken by the adult members. When a child becomes adult, he/she starts his/her own family, and the decision problem of that new family is not our concern in this model.

Consider first the preferences of the family. We assume that conditional on physical health and occupation, labour supply is not a choice for the families surveyed in our sample ${ }^{6}$. Hence we abstract away from the preference for leisure in the family utility functions. Preferences are of course defined over the family's per capita consumption expenditure, $c$, and over an index of children's education, $C E$, taking all the school-age children of the family into account (schooling decisions are considered for children in the age group 6 to 18). Further, and, for the context of this study, most importantly, mental health of the family $(M)$ and its physical health $(H)$ are also allowed to influence a family's utility.

\footnotetext{
${ }^{5}$ We assume children older than 18 are able to take decisions for themselves. The rationale for such an assumption is that in this latter age group $45 \%$ of the children live away from the family (for both HIV and NON HIV families). Hence it is not feasible to obtain all information on them. All expenditure on them, when they live with the family is treated as a negative transfer to the family. Analogously, the money they send or give the family is treated as a positive transfer to the family. .

${ }^{6}$ Only $6 \%$ of NON HIV males (who are less health constrained) do not work. For those who are working, we regress the number of days of work in a week on the wage per day, occupation, education, health status, a dummy for whether the male is HIV and the number of members in a family. We find that only the occupation dummies are significant. This suggests that, conditional on being able to work, one cannot choose the number of days of work. This is consistent with the common notion of India being a labour surplus economy.
} 
Consider mental health first. Mental health picks up many different effects in a compact form. While an ailing member in any family will feel worried about future health, income and children's upbringing, the HIV infected member will of course feel more miserable - shocked (after being diagnosed HIV positive), depressed, even more worried about future health, income and children's upbringing, and possible early death. In many cases, this worry may pass on to the spouse. In the case of HIV in particular, the spouse, in addition, might feel cheated, embarrassed and stigmatized.

In the context of physical health, we treat the current state of health as predetermined. ${ }^{7}$ However, for a given state of health, medical expenditures $m d$ can be expected to have a positive impact over expected future health, $H^{f}$, with $H^{f}=H^{f}(H, m d)$. But since $H^{f}$ is not observable, we postulate that the family's preference for expected future health is reflected in its current mental health: a significant component of mental health consists of the worry about future health and the family can take some relief by spending money on medicines $(\mathrm{md})$. That is, we postulate that, among other things, $H^{f}$ is a determinant of mental health.

As for the possible other determinants of mental health, following the emerging literature on mental health and subjective well-being and considering the specific case of HIV and the existence of extended family structure in India, we consider a host of factors like wealth, employment status, age, sex, HIV dummy, extended family dummy, and so on. Clubbing all these variables as the vector $X^{8}$ and incorporating $H^{f}(H, m d)$, we specify the following underlying relationship determining the mental health of a family:

$$
M=\delta_{0}+\delta_{1} \cdot m d+\delta_{2} \cdot H+\lambda \cdot X \text {. }
$$

Next consider children's education. Let $C E$ denote the index for children's education taking all the school-going age children of the family into account, and the

\footnotetext{
${ }^{7}$ While medical expenditures can be considered to improve health, poor physical health triggers higher medical expenditures. Consequently, medical expenditure and current physical health are negatively correlated in our sample. Due to the cross-section nature of our data we are not able to disentangle these two effects and therefore treat the current state of health as predetermined.

${ }^{8}$ See equation (9) below for the complete list of explanatory variables clubbed under $X$.
} 
family's preference is defined over this index $C E$. We describe below how we come up with an expression for $C E$ that is consistent with our sample.

Ideally an index of human capital accumulation by each child, $E$, should depend on the fraction of time the child spends studying $(e \in[0,1])$ and the quality of schooling $(\sigma)$, that is, $E=E(e, \sigma)$, and a choice of $e$ should be allowed by taking into account the opportunity cost of a child's time. We considered the opportunity cost of educating children in the form of lost income from working and allowing for a choice of $e \in[0,1]$. But only 52 out of a total of 892 children (ages 6-18) in our sample are child labourers and hence this cost is unimportant. Further, in our sample of school-age children, $47.5 \%$ study for 6 hours, 27\% study for 8 hours and 12\% study for 5 hours and these seem to depend on class and state of residence. Very little extra studying is done, which is not surprising for the education levels of the families in our sample. The lumping of studying hours implies that they are more or less synonymous with school hours. When we regress studying hours (for those attending school) on wealth, age, gender of the child and state dummies, only age and state dummies are significant. Thus school hours can be taken as exogenous. Hence in our specification, $e=\bar{e}$, that is, $E(e, \sigma)=E(\bar{e}, \sigma) \equiv E(\sigma)$. We postulate that $E(\sigma)=\sigma$. Since $E$ is the index of human capital accumulation for each child, it needs to be weighted by the proportion of school-going children $\left(P_{S}\right)$ in order to come up with an index for children's education for the entire family. ${ }^{9}$ Finally, we propose that quality of schooling $(\sigma)$ could be well-proxied by per capita schooling expenditure $(S C)$. Thus, the expression for $C E$ becomes: $C E=P_{S} \cdot S C$.

We observe that a significant proportion of families in our sample (48\%) do not have any children. Hence we assume that these families do not put any weight on children's education in their family utility function. Considering the discussion above, we postulate the following utility functions for the two broad family types:

\footnotetext{
${ }^{9}$ Proportion seems to be the right weight rather than the total number. Multiplying with the total number has the undesirable property that it gives undue advantage to having more children. We focus on the quality of a representative child. This differs from studies that use number of children as an argument in the utility function.
} 
Families with school-age children: $u=\alpha \log c+\beta \log (1+M)+\gamma \log \left(1+S C \cdot P_{S}\right),{ }^{10}$

Families without school-age children: $u=\alpha \log c+\beta \log (1+M)$.

Finally, consider the budget constraint faced by the family. Since we treat labour supply as exogenous, labour income of the family is given. This labour income, coupled with incomes from other sources like rental income and net external funding (transfers from relatives, loss of savings, sale of assets and debts), gives the total income of a family $(Y) .{ }^{11}$ The family allocates this total income between consumption expenditure $(c)$, medical expenditure $(m d)$, and schooling expenditure $\left(S C \cdot P_{S}\right)$ (in case of families with children), that is, the budget constraints for the two types of families are given by:

Families with children: $N \cdot c+m d+\left(S C \cdot P_{S}\right) \times n_{S} \leq Y$,

Families without children: $N \cdot c+m d \leq Y$.

Here $N$ is the family size and $n_{S}$ denotes the total number of children in the school-going age (between 6 and 18 years).

The Decision Problem of Families with Children:

$$
\begin{array}{cc}
\underset{\left\{c, m d, S C \cdot P_{S}\right\}}{\operatorname{Maximize}} & \alpha \log c+\beta \log (1+M)+\gamma \log \left(1+S C \cdot P_{S}\right) \\
\text { subject to (1) and (4). }
\end{array}
$$

The first-order conditions of this optimization problem give the following three equations which we take to the data for estimation.

\footnotetext{
${ }^{10}$ Since $P_{S}$ may be zero, the number one has been added to normalize the sub-utility from children of school age to be zero when $P_{S}$ is zero. One is also added to $M$, which, as explained in the next section, is measured as a latent variable that can possibly be zero.

${ }^{11}$ Note that the actual decision problem facing the family is intertemporal in nature with savings and dissavings adjusted optimally to brave the immediate disaster. This is evident from the large amounts of sales of assets, debts or loss of savings (included in net external funding) by the HIV families observed in the data. But, given the one-shot nature of our data, we cannot address this intertemporal decision problem. Instead, we analyze the intratemporal allocation problem where $Y$ stands for total spending.
} 


$$
\begin{aligned}
& N \cdot c=\left(\frac{\alpha}{\alpha+\beta+\gamma}\right) \cdot\left[Y+\frac{1+Z}{\delta_{1}}+n_{S}\right], \\
& m d=\left(\frac{\beta}{\alpha+\beta+\gamma}\right) \cdot\left[Y+\frac{1+Z}{\delta_{1}}+n_{S}\right]-\frac{1+Z}{\delta_{1}}, \\
& S C \cdot P_{S}=\frac{1}{n_{s}}\left(\frac{\gamma}{\alpha+\beta+\gamma}\right) \cdot\left[Y+\frac{1+Z}{\delta_{1}}+n_{S}\right]-1,
\end{aligned}
$$

where $Z=M-\delta_{1} \cdot m d$. Decision for families without children is a special case of the above.

\section{Estimation Procedure}

We estimate two different utility functions for families with school-age children and for those without them. Table A.1 in the Appendix has the summary statistics for all the variables used in our estimation. In each case we pool HIV and NON HIV families using weights ${ }^{12}$. All standard errors in the following analysis are robust. We describe the method for the case of families with school-age children. The method for the case without such children is exactly the same except that there is no schooling decision and hence one equation will be reduced.

\subsection{Mental Health Equation}

First consider the family mental health equation. Let us elaborate on the explanatory variables clubbed under vector $X$ in equation (1). Following the emerging literature on mental health and subjective well-being (see, for example, Andres, 2004; Blanchflower and Oswald, 2004, 2007; Case and Deaton, 2006; Helliwell, 2006), we include wealth $(W)$, whether any adult family member is unemployed $\left(D_{\text {UNEMP }}\right)$, the average age of adult family members $\left(A v \_a g e\right)$, the square of average age $\left(A v \_a g e^{2}\right)$ and a dummy for whether there is a female member in the family $\left(D_{F E M}\right)$. Also, considering

\footnotetext{
12 While collecting data, we looked for a main respondent and then surveyed his/her family. Thus our weighting procedure takes into account the probability of the main respondent being either male and HIV or female and HIV or male and NON HIV or female and NON HIV. For example, weight of a family with main respondent male HIV $=\frac{\text { Proportion of HIV males in population }}{\text { Proportion of HIV males in sample }}$.
} 
the specific case of HIV, we include an HIV dummy ( $D_{H I V}$ ) and the time span since the first detection of HIV in the family (ts). We allow for regional differences in mental health by defining a dummy variable for the northern states $\left(D_{\text {NоRTH }}\right)$ in our sample. Finally, considering the extended family structure in India and the possibility that an HIV family may get more emotional support in an extended family, we include a dummy variable, $D_{E X T}$, to denote whether a family is a part of an extended family. Thus, the estimable family mental health equation is:

$$
\begin{aligned}
M_{i}= & \delta_{0}+\delta_{1} \cdot m d_{i}+\delta_{2} \cdot H_{i}+\delta_{3} \cdot t s_{i}+\delta_{4} \cdot t_{i}{ }^{2}+\delta_{5} \cdot W_{i}+\delta_{6} \cdot D_{H V V i}+\delta_{7} \cdot D_{\text {FEMi }} \\
& +\delta_{8} \cdot D_{\text {EXTi }}+\delta_{9} \cdot D_{\text {UNEMPi }}+\delta_{10} \cdot A v_{-} a g e_{i}+\delta_{11} \cdot A v_{-} a g e_{i}{ }^{2}+\delta_{12} \cdot D_{\text {NORTHi }}+\omega_{i} \cdot
\end{aligned}
$$

The quadratic effect of $t s$ is meant to capture possible non-linear movement of mental health after one finds out about HIV in the family such as an initial shock and then acceptance of the fact or hopelessness.

Equation (9) is a technological relationship that relates how medical expenditure, physical health and the other explanatory variables translate into mental health of the family. Thus this equation can be estimated on its own. But before we do so, we have to deal with the fact that the mental health index we constructed from our data is an ordinal measure, whereas the mental health variable in equation (9) is a continuous measure. The data and our index are reconciled by assuming that the responses of families (given by the orderings) are based on an underlying latent mental health variable $M$, given in equation (9). We further assume that the errors in equation (9) follow a normal distribution, which results in an ordered probit model. Thus we estimate parameters $\delta_{0}$ to $\delta_{12}$ by ordered probit. ${ }^{13}$ Using these parameters we calculate the predicted value of $M$ for each family. We use the predicted value $\hat{M}$ for the rest of our empirical analysis as the (continuous) measure of mental health for each family.

\footnotetext{
${ }^{13}$ This is in line with Blanchflower and Oswald $(2004,2007)$ who use ordered logit. The qualitative results do not change if we assume a logit specification.
} 


\subsection{Consumption, Medical Expenditure and Schooling Equations}

There are three equations to estimate the underlying parameters when $S C \cdot P_{S}$ and $m d$ are strictly positive. Define

$$
\phi_{1} \equiv \frac{\alpha}{\alpha+\beta+\gamma}, \phi_{2} \equiv \frac{\gamma}{\alpha+\beta+\gamma} \text { and } \phi_{3} \equiv \frac{\beta}{\alpha+\beta+\gamma} .
$$

Then the estimable consumption, medical expenditure and schooling equations are:

$$
\begin{gathered}
N_{i} \cdot c_{i}=\phi_{1} \cdot\left[Y_{i}+\frac{1+Z_{i}}{\delta_{1}}+n_{S i}\right]+\varepsilon_{1 i}, \\
n_{S i} \cdot\left(1+S C_{i} \cdot P_{S i}\right)=\phi_{2} \cdot\left[Y_{i}+\frac{1+Z_{i}}{\delta_{1}}+n_{S i}\right]+\varepsilon_{2 i}, \\
m d_{i}=\phi_{3} \cdot\left[Y_{i}+\frac{1+Z_{i}}{\delta_{1}}+n_{S i}\right]-\frac{1+Z_{i}}{\delta_{1}}+\varepsilon_{3 i},
\end{gathered}
$$

where $Z_{i}=M_{i}-\delta_{1} \cdot m d_{i}$.

Equations (10), (11) and (12) form a seemingly unrelated system of equations (SURE) for the family. However, since the three add up to income in the budget constraint, only two of them can be used for estimation. We use equations (10) and (11). Notice that they have the same regressors. Hence system OLS is consistent and efficient and reduces down to doing OLS equation by equation.

An issue of concern using OLS equation by equation is the possibility of selection bias. In the structural model, these equations hold for positive $m d, c$ and $S C . P_{S}$, so we use only the observations when these conditions hold. However one can argue, a la Heckman, that these make the estimates inconsistent. To check for that we ran the models on the full sample with Heckman corrections but since $m d$ and SC.P $P_{S}$ are zero for a very small proportion of our sample (about $10 \%$ for both), the estimates were almost identical. Therefore the OLS parameters are consistent and efficient.

The OLS regressions yield $\hat{\phi}_{1}$ and $\hat{\phi}_{2}$, whereas $\hat{\phi}_{3}$ is derived from the model

restriction: $\hat{\phi}_{1}+\hat{\phi}_{2}+\hat{\phi}_{3}=1$. For the sample without school-age children we first estimate 
the mental health "technology" equation. Since there is no schooling decision, we only estimate equation (10).

\section{Estimation Results}

First let us look at the determinants of mental health. Table A.2 in the Appendix reports the ordered probit estimates with the full set of possible explanatory variables as specified in equation (9). Since only a subset of variables is significant, and we would like to use the predicted value $\hat{M}$ for the estimation of preference parameters, we conduct a joint significance of a subset of variables that are insignificant in themselves (Table A.3 in the Appendix) and, based on this Wald test, we drop the insignificant variables and then re-estimate equation (9) with only the significant variables. The results for both measures of mental health, $I M H_{1}$ and $I M H_{2}$, are reported in Table 3.

Since these are not the marginal effects, we only discuss the signs of the coefficients and not the magnitudes. For both measures, better current physical health leads to better mental health. Controlling for current physical health, the higher the medical expenditure the higher is the mental health. This is an important result for our model. We contend that, controlling for current physical health, people who spend more money on medical expenditure, do so to affect their expected future health. The significant and large coefficient on $D_{H I V}$ suggests that HIV infection affects mental health negatively.

The effects of other variables are specific to the measure of mental health considered. With $\mathrm{IMH}_{2}$, we get the "U” shaped relation between mental health and age, as well documented in the recent well-being literature. The coefficients of time span suggest that, controlling for physical health, the measure based on self reported depression gets better as more time passes and the non-linearity is not evident. Wealth affects $I M H_{1}$ positively. Belonging to an extended family increases mental health $\left(I M H_{1}\right)$, as expected. The results using $I \mathrm{IH}_{2}$ also suggest that women have a lower mental health than men. The basic flavor of our results is not too different if we assume a logistic distribution instead of normal distribution for the error term. 
As mentioned earlier, we now use the ordered probit estimates to convert the ordinal ranking in our mental health measure to a continuous quantitative measure given by the latent variable underlying the ordered probit model. We use this continuous measure in our empirical analysis below including the estimation of equations $(10-12)$. For the remaining part of the paper, we report the results using $I M H_{1}$ as it uses all our questions reflecting depression (results are similar with $\mathrm{IMH}_{2}$ ).

Table 4 reports the estimates of the parameters of the consumption and schooling equations. The estimate of parameter relating to mental health is computed by subtracting the sum of the reported estimates from one. The relative magnitudes confirm the observation made by the doctors and HIV counselors: mental health (which in turn depends on current and expected future physical health) in the family utility function is much more important than consumption or children's education. For example, to keep a family (with school going age children) at the same level of utility as would be obtained at the mean values of all variables, per capita consumption expenditure has to be reduced by Rs. 818 if mental health is increased by one standard deviation. This is almost equal to mean value of per capita consumption. This is equally true when we consider the substitution between the education variable and mental health. This points out to the importance of mental health in the utility function.

\section{An Example: Welfare Loss to a Family due to HIV/AIDS}

In this section, we illustrate the importance of taking into account mental health in the utility function. Consider Table 5. If one compares HIV and NON HIV families, there is no significant difference between them in terms of per capita consumption and children's education. Therefore, if one were consider only these dimensions, one would, absurdly, conclude that HIV families are equally well off as the NON HIV families ${ }^{14}$. However, there is a vast difference in the mental health of HIV and NON HIV families. In this context, it would seem important to include the mental dimension in calculating the utility loss to households.

\footnotetext{
${ }^{14}$ These are of course financed through dissavings, sale of assets, increase in debts or increase in monetary transfers from relatives; all of which have long run dynamic effects. These are not considered in this paper.
} 
We illustrate this point with a simple example wherein we calculate the welfare loss to a household from HIV/AIDS. Using the utility function parameters estimated above, we consider a commonly used welfare loss measure: the Compensating Variation (CV) to find the income equivalent of welfare loss to an average family due to HIV/AIDS $\left(\tau^{i j}\right)^{15}$. Given the Cobb-Douglas utility specification, solving the expression for $\tau^{i j}$ for families with school-age children yields:

$$
\tau^{i j}=\left[Y^{i}+\frac{1+Z^{i}}{\delta_{1}}+n_{s}{ }^{i}\right] \cdot\left[\frac{N^{j}}{N^{i}}\right]^{\frac{\alpha}{\alpha+\beta+\gamma}} \cdot\left[\frac{n_{s}{ }^{j}}{n_{s}{ }^{i}}\right]^{\frac{\gamma}{\alpha+\beta+\gamma}}-\left[Y^{j}+\frac{1+Z^{j}}{\delta_{1}}+n_{s}{ }^{j}\right] .
$$

For families without school-age children:

$$
\tau^{i j}=\left[Y^{i}+\frac{1+Z^{i}}{\delta_{1}}\right] \cdot\left[\frac{N^{j}}{N^{i}}\right]^{\frac{\alpha}{\alpha+\beta}}-\left[Y^{j}+\frac{1+Z^{j}}{\delta_{1}}\right] .
$$

Here the reference family $i$ is an average NON-HIV family and family $j$ is an average HIV family.

The total welfare loss for a HIV family, averaging across families with and without school going age children, is Rs. 90,012 per month. In order to highlight the importance of integrating mental health in welfare evaluation, Table 6 reports the various disaggregates of the money equivalent expression given in equations (13a) and (13b). While HIV families actually have a larger expenditure $Y$ as compared to NON HIV families, the difference pales when compared to the difference in $\frac{1+Z}{\delta_{1}}$. It is this component that drives the welfare loss. The estimates for $\frac{1+Z}{\delta_{1}}$ come from the mental health technology and emphasize the role of mental health in our analysis.

Such a huge magnitude is not surprising because it reflects the private valuation of one's life as well as the cost of stigma for being HIV positive. Blanchflower and Oswald (2004), the only work we are aware of that has tried to quantify welfare losses using subjective well-being estimates, also come up with similar large figures. They estimate that a typical individual in the US or Britain would need $\$ 100,000$ per annum to

\footnotetext{
${ }^{15}$ The choice of welfare measure is to just illustrate our point. Our point would be equally true if we considered alternate measures like Equivalent Variation.
} 
compensate for the well-being loss resulting from divorce. The corresponding figure for job loss for an average male is $\$ 60,000$ per annum.

\section{Robustness}

We have carried out two robustness checks to validate our exercise: first, with respect to the choice of mental health index, and second, with respect to the choice of the utility function.

\subsection{Choice of Mental Health Index}

Although we have presented most of the results using $\mathrm{IMH}_{1}$ (minimum of the points across all the mental health questions answered by the respondent), but, time and again, we have also compared them with $\mathrm{IMH}_{2}$, the index that uses responses to only one question: “I felt depressed”. The mental health technology equation estimates somewhat differ depending on which index one uses (see Table 3). But the significance and magnitudes of the key variables like $m d, H$ and $D_{H I V}$ are not very different so that when we use the estimates to calculate the welfare losses, the cost is around Rs. 114,996 per HIV family per month.

\subsection{Choice of the Utility Function}

Since the analysis has been done using a Cobb-Douglas utility function, a natural question that emerges is how sensitive the results are to an alternative specification of the utility function. We redo our exercise with Constant Elasticity of Substitution (CES) utility function for the general model and get very similar results. ${ }^{16}$ The cost per family is Rs. 88,063 per month. The reason for the robustness lies in the fact that in almost all specifications in this family of CES utility functions, when calculating the money equivalent, the main loss comes from $\frac{1+Z}{\delta_{1}}$.

\footnotetext{
${ }^{16}$ The details of the CES estimation are available from the authors on request.
} 


\section{Conclusion}

This paper presents simple measures of family mental health indices based on axiomatic foundations and integrates mental health into the neoclassical model that allows for proper substitution possibilities in the family preferences and quantifies its significance in family utility along with its other arguments. It is an example of measuring and modeling what has traditionally been treated as part of unobserved heterogeneity in empirical models.

Using primary household data we estimate household utility function parameters that measure the relative importance of consumption, schooling of children and mental and physical health effects. Since mental health is not directly observable, we first compute an ordinal measure based on a series of questions following Case and Deaton (2006). Then we apply an ordered probit model on the measure to obtain a continuous measure based on medical expenditure, current health, wealth, HIV status, extended family status, age and sex. This continuous measure is then used to estimate the parameters of the family utility function. We find that mental health effects are far more important than the effect of consumption or children's schooling in determining utility.

We show the importance of integrating mental health in the utility function by considering the case of HIV/AIDS in India. We find that while there are no significant differences in per capita consumption and schooling between HIV and NON-HIV families, there is a considerable difference in their mental health. We quantify this impact on mental health by integrating it in welfare evaluation. This becomes possible as medical expenditure, a choice variable in the family optimization problem, turns out to be a significant determinant of mental health. While other studies like Case and Deaton (2006) and Kling, Liebman and Katz (2007) do consider mental health effects, most of them have not tried to quantify it. In the literature, Blanchflower and Oswald (2004) is the only work we are aware of that has used the coefficients of subjective well-being equation to quantify welfare losses from incidence of divorce or job loss. While they have compared the relative sizes of the coefficients of income and divorce in a regression equation like the one reported in Table 3, and calculated how income has to change to 'compensate' for divorce to maintain the same level of well-being, we estimate a 
structural model to take into account the trade-off in the preferences to calculate the welfare loss.

While we have selected a health context to integrate mental health, the case for its inclusion is much broader. With increasing importance being given to mental well being, it is important to be able to value it to make it comparable to conventional measures of welfare, for example consumption expenditure. Our paper shows that as long as there is a choice variable that can affect mental well-being, it can be integrated into conventional analysis.

Besides the use of our mental health measure in other contexts, we hope our results will encourage future research to pay attention to factors that are typically treated as unobserved heterogeneity and attempt to obtain measures for them (even if crude). This may go a long way in improving our understanding of the issues of interest. 


\section{References}

[1] Andres, A.R. (2004), "Determinants of Self-reported Mental Health Using the British Household Panel Survey,” Journal of Mental Health Policy and Economics, vol. 7(3), 99-106.

[2] Banerjee, A., Deaton, A. and Duflo, E. (2004), "Wealth, Health, and Health Services in Rural Rajasthan,” American Economic Review (Papers and Proceedings), 94 (2), 326-30.

[3] Blanchflower, D.G. and Oswald, A.J. (2004), "Well-being over Time in Britain and the USA,” Journal of Public Economics, vol. 88, 1359-86.

[4] Blanchflower, D.G. and Oswald, A.J. (2007), "Is Well-being U-shaped over the Life Cycle?” NBER Working Paper No. 12935.

[5] Case, A. and Deaton, A. (2006), "Health and Well-Being in Udaipur and South Africa," forthcoming in Developments in the Economics of Aging, ed. by David Wise, University of Chicago Press.

[6] Clark, A. and Oswald, A. (1994), "Unhappiness and Unemployment," Economic Journal, vol. 104, 648-59.

[7] Clark, A. and Oswald, A. (1997), "Happiness and Economic Performance," Economic Journal, vol. 107, 1815-31.

[8] Easterlin, R. (2003), “Explaining Happiness,” Proceedings of the National Academy of Sciences, vol. 100 (19), 11176-83.

[9] Frey, B.S. and Stulzer, A. (2002), Happiness and Economics, Princeton University Press: Princeton.

[10] Gilbert, D. (2006), Stumbling on Happiness, Alfred A Knopf: New York.

[11] Graham, C. (2007), “The Economics of Happiness,” in The New Palgrave Dictionary of Economics, eds., S. Durlauf and L. Blume, Second Edition (forthcoming).

[12] Helliwell, J.F. (2006), “Well-being, Social Capital and Public Policy: What's New?” Economic Journal, vol. 116, C34-C45. 
[13] Kahneman, D., Krueger, A.B., Schkade, D., Schwarz, N. and Stone, A.A. (2006), "Would You be Happier if You were Richer? A Focusing illusion," Science, vol. 312, 1908-1910.

[14] Keane M. (2006), Structural Vs. Atheoretic Approaches to Econometrics, Keynote address at the Duke Conference on Structural Models in Labor, Aging and Health, September 17-19, 2005.

[15] Kling, J., Liebman, J. and Katz, L. (2007), "Experimental Analysis of Neighborhood Effects,” Econometrica, vol. 75 (1), 83-119.

[16] Layard, R. (2005), Happiness: Lessons from a New Science, Allen Lane: London.

[17] Sen, A. (1986), "Social Choice Theory", in Handbook of Mathematical Economics, ed. by K. J. Arrow and M. D. Intriligator, North-Holland, vol. 3, 1073-1181. 
Table 1: Physical Health Index

\begin{tabular}{lc}
\hline & Health index \\
\hline HIV & $8.5(1.5)$ \\
Average Family & \\
NON HIV & $10.3(0.8)$
\end{tabular}

(Standard errors are in the parentheses.)

Table 2: Mental Health: Relative Frequency (in \%)

\begin{tabular}{llccc}
\hline & \multicolumn{2}{c}{ HIV families } & \multicolumn{2}{c}{ NON HIV families } \\
& $\mathrm{IMH}_{1}$ & $\mathrm{IMH}_{2}$ & $\mathrm{IMH}_{1}$ & $\mathrm{IMH}_{2}$ \\
\hline Most of the time (1) & 82.43 & 57.77 & 37.74 & 5.76 \\
Sometimes (2) & 14.05 & 28.34 & 17.82 & 15.57 \\
Hardly Ever (3) & 3.24 & 7.36 & 24.95 & 23.67 \\
Never (4) & 0.27 & 6.54 & 19.50 & 55.01 \\
\hline
\end{tabular}


Table 3: Mental Health: Ordered Probit Estimates

\begin{tabular}{ccc}
\hline & $I M H_{1}$ & $I M H_{2}$ \\
\hline$m d$ & $0.000018^{* *}$ & $0.000016^{*}$ \\
$H$ & $0.248^{* * *}$ & $0.172^{* * *}$ \\
$W$ & & $0.098^{* *}$ \\
$D_{H I V}$ & $0.00000146^{* * *}$ & \\
$D_{F E M}$ & $-1.20^{* * *}$ & $-1.73^{* * *}$ \\
$D_{E X T}$ & & $-0.71^{* * *}$ \\
Av_age & $0.68^{* * *}$ & \\
Av_age & & $-0.87^{* *}$ \\
$D_{\text {NORTH }}$ & $0.0002^{*}$ & $0.001^{* *}$ \\
\hline No. of Observations & & $-0.26^{*}$ \\
Log Pseudo Likelihood & 829 & $833^{\#}$ \\
$\chi^{2}$ & -432.92 & -799.60 \\
Pseudo $R^{2}$ & $181.90^{* * *}$ & $369.79^{* * *}$ \\
& 0.10 & 0.09 \\
\hline & \#: No. of Observations differ due to missing data.
\end{tabular}

Table 4: Estimates from Consumption, Schooling and the Transformed Medical Expenditure Equation

\begin{tabular}{cccc}
\hline & $\begin{array}{c}\text { With School } \\
\text { Age-Children } \\
\left(n_{s}>0\right)\end{array}$ & $\begin{array}{c}\text { With School } \\
\text { Age-Children } \\
\left(n_{s}>0\right)\end{array}$ & $\begin{array}{c}\text { Without School } \\
\text { Age- Children } \\
\left(n_{s}=0\right)\end{array}$ \\
\hline$\hat{\phi}_{1}$ & $0.014^{* * *}$ & & $0.0172^{* * *}$ \\
$\hat{\phi}_{2}$ & 326 & $0.002^{* * *}$ & \\
\hline No. of Observations & 0.68 & 326 & 348 \\
$R^{2}$ & \multicolumn{3}{r}{$\left({ }^{* * *}\right.$ significant at $\left.1 \%\right)$}
\end{tabular}


Table 5: Per Capita Expenditure, Schooling and Mental Health

\begin{tabular}{lccc}
\hline & $c$ & $S C^{*} P_{S}$ & $\hat{M}$ \\
\hline NON HIV Families & 951 & 65 & 3.27 \\
HIV Families & $(1060)$ & $(128)$ & $(0.44)$ \\
& 1006 & 69 & 1.62 \\
& $(1170)$ & $(166)$ & $(0.46)$ \\
\hline
\end{tabular}

Table 6: Decomposition

\begin{tabular}{lllll}
\hline & $Y$ & $N$ & $n_{s}$ & $\frac{1+Z}{\delta_{1}}$ \\
& & & & \\
With School-Age Children & & & & \\
NON HIV Families & 2,320 & 4.31 & 2.10 & 230,953 \\
HIV Families & 2,763 & 3.77 & 1.91 & 142,206 \\
Without School-Age Children & & & & \\
NON HIV Families & 2,432 & 1.81 & 0 & 239,831 \\
HIV Families & 3,269 & 1.98 & 0 & 146,133 \\
\hline
\end{tabular}




\section{Appendix}

Table A.1: Summary Statistics

\begin{tabular}{|c|c|c|}
\hline & $\begin{array}{c}\text { Weighted } \\
\text { Mean }\end{array}$ & Std Dev. \\
\hline Per Capita Monthly Consumption Expenditure (c )(Rs.) & 819 & 912 \\
\hline Quality Adjusted School Attendance ( $P_{S .} S C$ ) (Rs.) & 58 & 122 \\
\hline Medical Expenditure ( $m d$ ) (Rs.) & 119 & 326 \\
\hline Family Size $(N)$ & 3.16 & 1.78 \\
\hline Average Physical Health of Family $(H)$ & 10.31 & 0.90 \\
\hline Time Span since HIV Detection (ts) (Yrs.) & 0.0001 & 0.0002 \\
\hline Wealth (W) (Rs.) & 14,694 & 26,497 \\
\hline Number of School Going Age Children $\left(n_{s}\right)$ & 1.17 & 1.005 \\
\hline Family Resides in North India ( $D_{\text {NORTH }}$ ) & .571 & 0.49 \\
\hline Family has Female Adult Member ( $D_{F E M}$ ) & 0.86 & 0.34 \\
\hline Patient Lives in an Extended Family ( $D_{E X T}$ ) & 0.59 & 0.49 \\
\hline Family has at least one Unemployed Adult ( $D_{\text {UNEMP }}$ ) & 0.04 & 0.19 \\
\hline Average Age of Adult Members (Av_age) & 34 & 10.2 \\
\hline Predicted Value of Mental Health $(\hat{M})$ & 3.25 & 0.47 \\
\hline Number of Observations & 850 & \\
\hline
\end{tabular}


Table A.2: Mental Health: Ordered Probit Estimates

\begin{tabular}{|c|c|c|}
\hline & $I M H_{1}$ & $\mathrm{IMH}_{2}$ \\
\hline$D_{\text {NORTH }}$ & $\begin{array}{r}\mathbf{- 0 . 0 5 6} \\
(0.77)\end{array}$ & $\begin{array}{l}\mathbf{- 0 . 2 4} \\
(0.09)\end{array}$ \\
\hline$m d$ & $\begin{array}{c}\mathbf{0 . 0 0 0 0 1 9 1} \\
(0.037)\end{array}$ & $\begin{array}{c}\mathbf{0 . 0 0 0 0 1 8 1} * \\
(0.052)\end{array}$ \\
\hline$H$ & $\begin{array}{c}\mathbf{0 . 2 7 6}^{* * *} \\
(0.00)\end{array}$ & $\begin{array}{c}\mathbf{0 . 1 7 6}^{* * *} \\
(0.001)\end{array}$ \\
\hline ts & $\begin{array}{c}\mathbf{- 0 . 2 1} \\
(0.19)\end{array}$ & $\begin{array}{l}-\mathbf{- 0 . 0 2} \\
(0.88)\end{array}$ \\
\hline$t s^{2}$ & $\begin{array}{c}\mathbf{0 . 0 3} \\
(0.19)\end{array}$ & $\begin{array}{c}\mathbf{0 . 2 1} \\
(0.34)\end{array}$ \\
\hline$W$ & $\begin{array}{c}\mathbf{0 . 0 0 0 0 0 1 2} \\
(0.03)\end{array}$ & $\begin{array}{c}\mathbf{0 . 0 0 0 0 0 0 4 9} \\
(0.67)\end{array}$ \\
\hline$D_{H I V}$ & $\begin{array}{c}-\mathbf{0 . 9 0 * * *} \\
(0.00)\end{array}$ & $\begin{array}{c}-\mathbf{1 . 6 1} * * * \\
(0.00)\end{array}$ \\
\hline$D_{F E M}$ & $\begin{array}{c}-\mathbf{0 . 3 2} \\
(0.13)\end{array}$ & $\begin{array}{c}-\mathbf{- 0 . 7 0} \text { *** } \\
(0.00)\end{array}$ \\
\hline$D_{E X T}$ & $\begin{array}{c}\text { 0.55*** } \\
(0.004)\end{array}$ & $\begin{array}{c}\mathbf{0 . 0 2 5} \\
(0.854)\end{array}$ \\
\hline$D_{U N E M P}$ & $\begin{array}{c}\mathbf{- 0 . 3 3 1} \\
(0.16)\end{array}$ & $\begin{array}{l}\mathbf{- 0 . 1 6} \\
(0.39)\end{array}$ \\
\hline Av_Age & $\begin{array}{l}\mathbf{- 0 . 0 5} \\
(0.27)\end{array}$ & $\begin{array}{c}-\mathbf{- 0 . 0 8 7 *} \\
(0.06)\end{array}$ \\
\hline$A v \_A g e^{2}$ & $\begin{array}{l}\mathbf{0 . 0 0 0 9} \\
(0.14)\end{array}$ & $\begin{array}{c}\mathbf{0 . 0 0 1 3} * * \\
(0.02)\end{array}$ \\
\hline No. of Observations & 829 & $820^{\#}$ \\
\hline Log Pseudo Likelihood & -424.34 & -784.87 \\
\hline$\chi^{2}$ & $187.99 * * *$ & $369.79 * * *$ \\
\hline Pseudo $R^{2}$ & 0.12 & 0.09 \\
\hline
\end{tabular}

Table A.3: Joint Test of Significance

\begin{tabular}{c|c}
\hline$I M H_{1}$ & $I M H_{2}$ \\
\hline $\mathrm{H}_{0}: D_{\text {NORTH }}=t s=t s^{2}=D_{F E M}=D_{U N E M P}=A v \_A g e=0$ & $\mathrm{H}_{0}: t s^{2}=W=D_{U N E M P}=D_{E X T}=0$ \\
\hline Verdict: Cannot reject $\mathbf{H}_{\mathbf{0}}$ & Verdict: Cannot reject $\mathbf{H}_{\mathbf{0}}$ \\
$\chi^{2}(7)=6.97$ & $\chi^{2}(6)=2.26$ \\
Prob $>\chi^{2}=0.32$ & Prob $>\chi^{2}=0.69$ \\
\hline
\end{tabular}

